\title{
PROCEDENCIA LA ACCIÓN DE TUTELA CONTRA SENTENCIAS DE TUTELA DE CONFORMIDAD CON LA SENTENCIA SU- 627 DEL 2015 DE LA CORTE CONSTITUCIONAL DE COLOMBIA.
}

\author{
Mónica Vega Hernández ${ }^{1}$ \\ Norly Villegas Peña ${ }^{2}$
}

\section{Resumen}

La acción de tutela es considerada hoy día como una de las mayores innovaciones constitucionales a partir de la entrada en vigencia de la Constitución Política de 1991, siendo una de las herramientas jurídicas más utilizada y con mayor incidencia en todos los aspectos de la vida social y política del país. Por tal motivo, es necesario evaluar aquellos casos en los cuales se ha admitido su procedencia, y de forma específica, aquellos casos en los cuales se admite la procedencia excepcional de esta figura contra sentencias de tutela. El objeto central de este proyecto de grado es determinar si de acuerdo con la jurisprudencia de la Corte Constitucional es procedente la interposición de la acción de tutela contra sentencias de tutela, con el fin de salvaguardar el derecho fundamental al debido proceso. Esta investigación es de tipo descriptiva con enfoque cualitativo, y se utilizó como método el inductivo para analizar las posiciones doctrinales y jurisprudenciales frente al tema planteado. Se obtuvo como conclusión que, de acuerdo con la jurisprudencia actual de la Corte Constitucional es procedente la interposición de la acción de tutela contra sentencias de tutela, con el fin de salvaguardar el derecho fundamental al debido proceso en los eventos de violaciones graves al debido proceso y las derivadas de la cosa juzgada fraudulenta cuando ella se advirtiera en el fallo de tutela demandado. Así, se han fijado reglas formales de procedencia excepcional de la solicitud de amparo

1 Especialista en Procesal Civil de la Corporación Universitaria del Caribe CECAR, Abogada.monica.vega@cecar.edu.co

2 Especialista en Procesal Civil de la Corporación Universitaria del Caribe CECAR, Abogada norly.villegas@hotmail.com 
en contra de providencias judiciales de tutela, cuando se advierta la cosa juzgada fraudulenta, en cumplimiento de ciertos requisitos y sobre las actuaciones propias del trámite tutelar.

Palabras clave: Tutela, cosa juzgada, debido proceso, cosa juzgada fraudulenta.

\section{Abstract}

The action of guardianship is considered to be today one of the major constitutional innovations from the entry in force of the Political Constitution of 1991, being one of the juridical tools more used and with major incident in all the aspects of the social life and politics of the country. For such a motive, it is necessary to evaluate those cases into which his origin has been admitted, and of specific form, those cases into which is admitted the exceptional origin of this figure against judgments of guardianship. The central object of this project of degree is to determine if in agreement with the jurisprudence of the Constitutional Court there is proceeding the interposition of the action of guardianship against judgments of guardianship, in order to safeguard the fundamental right to the due process. This investigation is of type descriptive with qualitative approach, and the inductive one was in use as method for analyzing the doctrinal and juriprudential positions opposite to the raised topic. There was obtained as conclusion that, in agreement with the current jurisprudence of the Constitutional Court there is proceeding the interposition of the action of guardianship against judgments of guardianship, in order to safeguard the fundamental right to the due process in the events of serious violations to the due process and the derivatives of the thing judged fraudulent when she was becoming aware in the failure of guardianship demanded. This way, there have been fixed formal rules of exceptional origin of the request of protection in opposition to judicial decisions of guardianship, when one warns the thing judged fraudulent, in fulfillment of certain requirements and on the own actions of the tutelary step.

Keywords: Guardianship, judged thing, owed process, thing judged fraudulent. 


\section{Introducción}

Este estudio pretende determinar si de acuerdo con la jurisprudencia de la Corte Constitucional es procedente la interposición de la acción de tutela contra sentencias de Tutela, con el fin de salvaguardar el debido proceso. Para ello se realiza un análisis de enfoque cualitativo, de carácter descriptivo y causal en tanto se realiza un examen crítico de la postura de la Corte Constitucional orientada a expandir el criterio fijado por esa misma corporación. Se utilizó como método el inductivo, pues en esta resulta necesario partir de situaciones particulares, tal como es el caso de las generalidades y regulación de la acción de tutela, con el propósito de que posteriormente se logre establecer un análisis general de la procedencia excepcional de la acción de tutela contra sentencias de la misma clase. Logrando así obtener resultados satisfactorios.

Para alcanzar el objetivo planteado, se procedió en primera medida a describir las características y procedencia general de la acción de tutela, especialmente en contra de providencias judiciales. Posteriormente se analizó la jurisprudencia de la Corte Constitucional que frente a ese tema esta corporación ha emitido; se dividió el estudio en cuatro fases a saber, por un lado, una primera etapa conformada por el fallo SU- 1219 de 2001 y las sentencias que conforme a ese precedente se expidieron; por otro lado, una segunda fase conformada por las sentencias T-218 de 2013 y SU- 627 de 2015 por las cuales el Tribunal constitucional dio vía libre para la procedencia de la tutela contra tutela. Luego se analizaron las condiciones bajo las cuales la corporación constitucional fijo la procedencia de la tutela contra tutela y finalmente se procedió con el análisis crítico de la postura.

Esta investigación se justifica ya que la misma permitirá a los estudiantes de las facultades de derecho del país profundizar en el estudio del mecanismo de protección más importante a nivel constitucional, como lo es la acción de tutela y como el ejercicio de esta herramienta de amparo puede resultar limitada cuando se busque la protección del derecho fundamental al debido proceso vulnerado con ocasión de una sentencia de tutela. Así mismo, la crítica realizada permitirá proponer nuevas formas de garantizar el debido proceso conculcado por una sentencia de tutela, para así enriquecer el debate académico y jurídico en relación con el tema bajo estudio.

En virtud, del artículo 86 de la Constitución Política de 1991, la acción de tutela es uno de los mecanismos más importantes en materia de defensa de los derechos fundamentales en Colombia, siendo una 
de las herramientas jurídicas más utilizada y con mayor incidencia en todos los aspectos de la vida social y política del país. En efecto, de acuerdo con el citado artículo la acción de tutela se puede definir como una acción subsidiaria, residual y autónoma, dirigida a permitir el control constitucional de las acciones de las autoridades públicas y excepcionalmente de los particulares, la cual puede ser interpuesta por cualquier persona que considere conculcados sus derechos fundamentales con el fin de evitar un perjuicio grave o irremediable, siempre que no exista otro medio de defensa para lograr tal fin.

Sin embargo, este tema no ha sido del todo pacífico, en la medida que, la procedencia de este mecanismo procesal ha suscitado diversos conflictos en el ámbito doctrinal y jurisprudencial, específicamente en lo que respecta a la procedencia o no de la acción de tutela contra sentencias de tutela. Al respecto, si bien la Corte Constitucional ha tratado de unificar jurisprudencia en torno a este tema, la misma ha sido objeto de múltiples cambios en los últimos años. Situación que no ha permitido consolidar y determinar los casos o circunstancias en los cuales procede o no la acción de tutela contra fallos de la misma naturaleza. Ejemplo de ello, lo constituye en un primer momento, la Sentencia SU-1219 de 2001, mediante la cual, la Corte Constitucional precisó de forma clara la improcedencia de la acción constitucional de amparo contra sentencias de tutela, en la medida que la constitución colombiana dispuso "las etapas básicas del procedimiento de tutela y previó que los errores de los jueces o inclusive las interpretaciones de los derechos constitucionales, siempre pudieran ser conocidos y corregidos por un órgano creado por él -para este caso- la Corte Constitucional, y por un medio establecido por él, el mecanismo de revisión" (Gómez, 2014).

Como argumentos de su negativa, precisó que, de permitirse la procedencia excepcional de una nueva tutela, se prolongaría indefinidamente el conflicto, ocasionando con ello el colapso del sistema de justicia, además, de generar una violación directa a la seguridad jurídica y a los derechos fundamentales que buscan ser protegidos. Ahora bien:

si bien este sería un problema real que se evitaría con la posición adoptada por la Corte, vale la pena anotar que este argumento es un retroceso a la postura acogida por la Corporación en materia de vía de hecho. En la medida que la Corte ya ha sostenido en reiterada jurisprudencia que, cuando existe una vía de hecho y hay necesidad de reconocerla a 
través de tutela, la protección del derecho fundamental al debido proceso prevalece sobre la seguridad jurídica de una sentencia en firme. Por lo tanto, ante la existencia de una vía de hecho este derecho fundamental se garantiza con la protección a través de la tutela y no con el respeto del criterio restringido de cosa juzgada. (Cuéllar, 2002, pág. 164)

Sin embargo, en concordancia con lo dispuesto por López Cuéllar (2002) estás solas circunstancias no deberían considerarse como argumentos definitivos que limiten la posibilidad de interponer una acción de tutela contra una sentencia de tutela, toda vez que, si bien el mecanismo de selección para revisión realizado por la Corte, fue creado como una herramienta discrecional, con el fin de subsanar los errores de los jueces de instancia, constituyéndose así, como el mecanismo de cierre en materia de tutela; no puede obviarse el hecho que, debido a la naturaleza discrecional de esta figura y a la gran de cantidad de acciones de tutela que ingresan diariamente a este órgano, imposibilita el acceso de todos los casos a esta etapa.

Frente a esta situación, si bien es cierto según la opinión mayoritaria de la Corte, la cosa juzgada constitucional en materia de tutela, opera una vez es decidido el caso por la sala de revisión, si el caso fue seleccionado, o una vez precluida la oportunidad para insistir en la revisión, en caso contrario, sería errado afirmar que el proceso de selección para revisión sea catalogado como un mecanismo de cierre, dado su naturaleza discrecional e imperfecta. Así las cosas, el hecho de que la Corte Constitucional pueda seleccionar los casos en los cuales se haya configurado vulneraciones de derechos fundamentales, ello no implica que este organismo este en la obligación de hacerlo, dada la naturaleza discrecional de la figura de revisión. Ocasionando con ello, una posible perpetuación en la vulneración de los derechos fundamentales de aquellos casos que no fueron seleccionados para revisión por parte de este organismo.

En ese orden, catalogar la revisión como un mecanismo de cierre en materia de tutela, implicaría desconocer y desproteger los derechos fundamentales de aquellos casos que no fueron seleccionados para tal fin. Por lo tanto, es importante entrar a analizar si esa categoría de órgano de cierre es aplicable en términos genéricos o absolutos, es decir, si se debe aplicar solo frente a las sentencias seleccionadas y falladas o frente a todas las sentencias que llegan a la Corte Constitucional para su eventual revisión. En efecto, los casos no seleccionados para revisión 
si hacen tránsito a cosa juzgada pero no constitucional, en la medida que, si llega a existir una vía de hecho en un caso no seleccionado, no se estaría frente a una cosa real sino aparente, haciendo admisible la interposición de una acción de tutela para subsanar la actuación vulneradora del derecho fundamental al debido proceso no subsanada en sede de revisión. En efecto,

Cuando se declara una vía de hecho no se agrega una instancia más, sino que se revisa si las instancias existentes deben o no permanecer incólumes; por eso la parte resolutiva de la tutela por vía de hecho no revoca el fallo, sino lo deja sin efectos. Desde ese punto de vista, la doctrina de la vía de hecho no contraría la cosa juzgada y no se configura como una nueva instancia (pág. 162).

Cabe precisar que, actualmente la Corte Constitucional con la sentencia SU-627 de 2015, abrió la posibilidad de interponer el mecanismo de amparo constitucional contra una sentencia de tutela, en aquellos casos donde se configure el fenómeno de cosa juzgada fraudulenta. Sin embargo, señaló que esta solo procede de manera excepcional siempre que la sentencia de tutela haya sido proferida por un juez o tribunal distinto a la Corte Constitucional. Es claro entonces que, esta Corporación reiteró su posición frente a la improcedencia de la acción de tutela contra una sentencia de la misma clase, bajo los mismos argumentos expuestos en la sentencia antes citada -SU 1219 de 2001, dejando de lado el análisis de aspectos de gran relevancia, como el hecho de que el mecanismo de revisión creado por la constitución no se puede traducir como "el órgano de cierre en materia de tutela", toda vez que, tal como se ha señalo en párrafos antecedentes, este es una figura discrecional, por lo tanto, la Corte puede o no seleccionar el caso para su eventual revisión, dejando por fuera muchos de los procesos de tutela en los cuales puede existir una violación grave al derecho fundamental del debido proceso, limitando con ello la posibilidad de que el afectado pueda hacer uso de la acción de amparo, pues según el sentir de la Corte se está ante una cosa juzgada de carácter constitucional.

Como se ha dicho, la posibilidad de interponer una acción de tutela contra un fallo de tutela no es un tema pacífico, toda vez que, para una parte tanto de la doctrina como de la jurisprudencia de la Corte Constitucional, abrir tal posibilidad implicaría generar un ambiente de inseguridad jurídica, en la medida que previamente, - al tratarse de un fallo de tutela-, se han garantizado todos los derechos fundamentales en 
cuestión. Por lo tanto, consideran que abrir tal posibilidad implicaría un desconocimiento de los procedimientos dispuestos por la Constitución Política, lo cual, a lo sumo, no representa un argumento viable para descocer la procedencia de la acción de tutela contra fallos de la misma naturaleza. En el contexto jurisprudencial y doctrinario descrito con antecedencia, la pregunta de investigación que se pretende resolver es: ¿Cuándo procede la acción de tutela contra sentencias de tutela de conformidad con la Sentencia SU- 627 del 2015 de la Corte Constitucional de Colombia?

La finalidad del presente trabajo investigativo radica en la necesidad de analizar la jurisprudencia emanada por la Corte Constitucional en torno al tema de la acción de tutela contra sentencias de la misma naturaleza, es decir, contra fallos de tutela. Al respecto, tal como se ha indicado anteriormente este tema ha sido objeto de innumerables debates al interior de la Corte, tal como se desprende de las sentencias emitidas por este organismo en los últimos años- sentencias: SU-1219/01, SU-627/15-. Ahora si bien, la postura general de la Corte se ha estado orientada en declarar la improcedencia de la acción de tutela contra sentencias de tutela, no se puede desconocer el hecho que los autos y sentencias que se expiden en el trámite de una acción de tutela pertenecen al género de providencias judiciales en las cuales se pude llegar a configurar una vía de hecho. En ese orden, el presente escrito tiene como objetivo realizar un análisis crítico del comportamiento de la jurisprudencia de la Corte Constitucional frente a este tema.

Cabe aclarar, que el análisis de este estudio permitirá a los estudiantes de las facultades de derecho del país profundizar en el estudio del mecanismo de protección más importante a nivel constitucional, como lo es la acción de tutela y como el ejercicio de esta herramienta de amparo puede resultar limitada cuando se busque la protección del derecho fundamental al debido proceso vulnerado con ocasión de una sentencia de tutela. Dicotomía que resulta no por menos paradójica, teniendo en cuenta que, tal como se desprende de la extensa jurisprudencia de la Corte Constitucional, los jueces de tutela en cumplimiento de su ejercicio, también incurrir en vías de hechos. Las cuales si bien, pueden ser subsanadas a partir del mecanismo de revisión dispuesto por la constitución, esta al ser una figura meramente discrecional, la Corte puede o no seleccionar determinados casos, dejando por fuera procesos donde eventualmente puedan existir graves violaciones a derechos fundamentales. 
En ese orden, esta investigación está orientada en generar un análisis crítico frente a la posición adoptada por la Corte como regla general de no admitir la procedencia de la acción de tutela contra sentencias de tutela, con el fin de enriquecer el debate académico y jurídico en relación con el tema bajo estudio. En efecto, este trabajo resulta de gran interés tanto para la sociedad en general como para la comunidad jurídica en particular, toda vez que, entra a debatir un tema que hasta ahora carece de la profundización necesaria tanto en el ámbito académico como jurídico. Es por ello, que a través de este escrito, se pretende motivar a la comunidad académica y en específico a la comunidad jurídica a seguir generando los espacios de análisis y debate necesarios, con el fin de llegar a generar nuevas propuestas que permitan ampliar el enfoque que se le ha dado a la improcedencia de la acción de tutela contra sentencias de tutela por parte de la Corte, pues no se debe olvidar que, los jueces de tutela si bien tienen como referente directo a la constitución, estos en su tarea como guarda de los derechos fundamentales, pueden incurrir en vías de hecho que vulneren el derecho fundamental al debido proceso. Cuyo objetivo general es el de determinar la procedencia la acción de tutela contra sentencias de tutela de conformidad con la Sentencia SU- 627 del 2015 de la Corte Constitucional de Colombia, desarrollados a través de los Objetivos específicos: Analizar normativa y jurisprudencialmente la figura de la acción de tutela en el marco del ordenamiento jurídico colombiano, Identificar el desarrollo jurisprudencial realizado por la Corte Constitucional con relación al tema de la procedencia de la acción de tutela contra sentencias de la misma naturaleza, Establecer la procedencia de la acción de tutela contra una sentencia de tutela, de acuerdo con las pautas dadas por la Corte Constitucional en la sentencia SU- 627 del 20 y realizar un análisis crítico de la posición actual adoptada por el Máximo Tribunal Constitucional frente a la procedencia de la acción de tutela contra sentencias de tutela.

\section{Metodología}

El enfoque de la presente investigación es cualitativo, toda vez que, parte de características esenciales que permitan identificar el fenómeno estudiado, utilizando la recolección de datos sin necesidad de medición numérica. La investigación realizada es de tipo descriptivo, puesto que está orientada a describir todos los aspectos fundamentales que conforman el tema objeto de debate, es decir que, se estudiará y analizará la postura fijada por la jurisprudencia de la Corte Constitucional en torno a si es procedente 
de manera excepcional interponer una acción de tutela contra un fallo de tutela, además de esto, dicha investigación es de tipo causal, en la medida que busca que, con el análisis de este tema, se establezca un análisis crítico, orientado a expandir el criterio fijado por la Corte Constitucional, en el cual no se limite la procedencia de esta figura solo para aquellos casos donde se configure una cosa juzgada fraudulenta, sino que por el contrario, sea procedente interponer acciones de tutela contra sentencias de tutela cuando se esté ante la existencia de una vía de hecho que afecte de manera directa el derecho al debido proceso.

El método utilizado para el desarrollo de la investigación es el método inductivo, pues en esta resulta necesario partir de situaciones particulares, tal como es el caso de las generalidades y regulación de la acción de tutela, con el propósito de que posteriormente se logre establecer un análisis general de la procedencia excepcional de la acción de tutela contra sentencias de la misma clase. Logrando así obtener resultados satisfactorios. Las técnicas de recolección de información dado que el enfoque de la investigación es cualitativo, serán las entrevistas que nos permitan obtener características específicas del tema objeto de estudio y las interpretaciones doctrinales y jurisprudenciales frente al tema.

\section{La acción de tutela en el ordenamiento jurídico colombiano: análisis normativo y jurisprudencial}

El objetivo primordial de este capítulo es analizar a la acción de tutela en el ordenamiento jurídico colombiano, concretamente el fin perseguido por el constituyente de 1991, generalidades, características y requisitos de procedencia de la misma. La acción de tutela constituye una de las más grandes novedades que a nuestro ordenamiento jurídico trajo la vigencia de la Constitución Política de 1991. Es reconocida por la doctrina como la institución más importante en el sistema judicial porque permite la protección expedita de los derechos fundamentales, pese a que éste mismo en las condiciones actuales es lento y difuso (Torres Ruda, 2014).

Si bien es cierto, es un mecanismo novedoso en nuestro sistema judicial; también es cierto que el mismo ya se encontraba presente en otros ordenamientos jurídicos continentales, específicamente en el estadounidense de donde data su más antiguo antecedente con el caso Marbury Vs Madison en 1801 (Torres Ruda, 2014), que marca el inicio en la implementación de una figura útil para salvaguardar derechos mínimos. 
Con posterioridad otras jurisdicciones en nuestro sistema continental han considerado la importancia en la protección de derechos individuales como México, país pionero en la utilización del mecanismo cuyo nomen iuris es el recurso de amparo, desde 1857 cuando fue estipulado en la constitución política de la época y luego reiterado en su constitución actual (Vivas Barrera, 2012). Así mismo, países como Brasil han dado vida al "mandamiento de seguridad", chile al "recurso de protección", Argentina, Costa Rica, Ecuador, Panamá y cerca de 13 países más (Ferrer Mac-Gregor, 2006).

Mismo instrumento es vislumbrado en países europeos como Alemania, España, Suiza, Albania, Croacia, Eslovenia, entre otros; países de África y Asia respectivamente (Ferrer Mac-Gregor, 2006). Sea cual sea el nombre que se le haya dado, resulta verdadero su consagración como instrumento útil para la protección de derechos mínimos, fundamentales e incluso humanos pues también ha sido extensivo al Derecho Internacional de los Derechos Humanos concretamente en distintas regulaciones como la Declaración universal de los derechos del hombre, la Convención americana de derechos humanos, entre otros; desde tal cúspide, se ha caracterizado al recurso de amparo (como suele llamarse en la gran mayoría de países) o acción de tutela como un mecanismo célere, sencillo, de fácil acceso, autónomo, de consagración constitucional y legal, tendiente a tener un juez natural que según la jurisdicción puede conocer del amparo en forma directa o en segunda o tercera instancia.

En nuestro país, el artículo 86 de la constitución política de 1991, la consagró como un mecanismo mediante el cual toda persona podría reclamar la protección de sus derechos constitucionales fundamentales cuando los mismos estuviesen siendo amenazados por acción u omisión de parte de una autoridad; a través de un procedimiento rápido y sumario que persiguiera tal fin (Const., 1991, Art 86). Posteriormente esa orden superior fue desarrollada a través del decreto 2591 de 1991, norma que integró la posibilidad excepcional de que la misma acción estuviese dirigida incluso en contra de particulares (Decreto 2591, 1991, Art 1). Con lo cual se puede definir a la acción de tutela como una "acción judicial subsidiaria, residual y autónoma, dirigida a permitir el control constitucional de las acciones $u$ omisiones de todas las autoridades públicas y excepcionalmente de los particulares" (Botero Marino, 2009), para "la defensa pronta y efectiva de los derechos fundamentales cuando ello resulte urgente para evitar un perjuicio irremediable o cuando no 
exista otro medio de defensa judicial que sirva para tales efectos" (Botero Marino, 2009)

Las características que revisten a la acción de tutela son en primera medida su naturaleza de acción judicial, con lo cual en la jurisdicción colombiana a diferencia de otras como la Mexicana, la tutela está concebida como un proceso judicial autónomo que surte unas etapas y se inicia a petición de parte a través de una solicitud informal (Art 14 del decreto 2591 de 1991), cuando se considere se está vulnerando un derecho consagrado constitucionalmente con el rango de fundamental (nominado), que a través de un juicio de constitucionalidad se haya elevado a esa categoría (innominados), porque estén conectados a uno expresamente fundamental (por conexidad) o porque se han definido "las políticas públicas de distribución de los recursos, los criterios de asignación, y los requisitos y procedimientos para el reconocimiento de derechos económicos, sociales y culturales, se constituyen derechos subjetivos que pueden ser exigidos en sede de tutela" (Corte Constitucional, sala primera de revisión, Sentencia T- 761, 2011) (Transmutación de derechos prestacionales a fundamentales); finalizando con un fallo con efecto interpartes que podrá ser recurrido ante el superior jerárquico del funcionario que profirió la decisión, caso en el cual se surtirá la segunda instancia cuya decisión podrá modificar el fallo recurrido. Sea impugnado o no, vale la pena resaltar que el fallo deberá ser enviado ante la Corte Constitucional a fin de que sea surtido el grado jurisdiccional de revisión. Adicionalmente según lo establece el artículo tercero del decreto 2591 de 1991, en el trámite del proceso se observarán los principios de "publicidad, prevalencia del derecho sustancial, economía, celeridad y eficacia" (Decreto 2591, 1991, Art 3).

Una segunda característica de la acción de tutela, en concordancia lo anterior, es que su trámite sea como lo establece (Botero Marino, 2009) de carácter sumarial, célere, oficioso, informal y preferente (pág. 132) dado a que se trata del amparo inminente de derechos fundamentales. Lo anterior significa i) que es corto y rápido pues como lo establece el artículo 29 del decreto 2591 de 1991 (Decreto 2591, 1991) una vez presentada la solicitud el fallador constitucional tiene diez (10) días para dictar el fallo en primera instancia y veinte (20) en segunda instancia para resolver el conflicto y decidir el amparo del derecho; ii) en gran proporción es impulsado por el juez sin que en todos los casos tenga que mediar solicitud de parte, pues es deber del juez de tutela adoptar los medios necesarios para que en caso de que encuentre "una 
grave e inminente violación o amenaza del derecho" (Decreto 2591, 1991, Art 18) pueda protegerlo de manera efectiva, teniendo incluso la posibilidad de modular los efectos del fallo de tutela a fin de garantizar la proteccion del derecho; y iii) es preferente, es decir, que el funcionario que tenga a su conocimiento la solicitud de amparo deberá sustanciarla con prelacion a otros procesos judiciales de naturaleza diferente, salvo aquellos relacionados con la proteccion del derecho fundamental de libertad protegido por el habeas corpus (Decreto 2591, 1991, Art 15).

En tercera medida, constituye una característica notable de la acción de tutela su naturaleza subsidiaria, es decir que la misma sólo es procedente cuando se hayan agotado todos los recursos ordinarios existentes, pues tal como lo manifiesta (Carrera Silva , 2011) "la finalidad de la acción de tutela no es la de sustituir medios judiciales existentes, sino por el contrario, garantizar su agotamiento" (pág. 80)

Como cuarta característica, se trata de una acción con un objeto especifico, la protección de derechos fundamentales; los cuales, si bien en un principio se predicaba de ellos su expreso enlistamiento en las prerrogativas consagradas en el título II de la carta política (derechos fundamentales nominados), hoy día con el avance jurisprudencial alcanzado por la Corte Constitucional es posible que la solicitud de tutela vaya encaminada al amparo de otros derechos que si bien no están expresamente consagrados como fundamentales "se encuentran implícitos en el ámbito de protección de distintas disposiciones jurídicas fundamentales" (Garzón Buenaventura, 2016, pág. 21) como se desprende del artículo 94 constitucional, derechos que la misma jurisprudencia ha denominado fundamentales innominados.

Así mismo, es posible respecto de otros derechos denominados por la jurisprudencia constitucional como fundamentales por conexidad, aquellos que siendo de económicos, sociales o culturales, son considerados fundamentales cuando aparezcan ligados de "manera inescindible con un principio o derecho fundamental" (Paz, 2012, pág. 1). Una cuarta posibilidad de protección de derechos no revestidos expresamente como fundamentales también pueden ser objeto de protección de tutela, noción que la Corte Constitucional ha denominado "transmutación de derechos prestacionales en un derecho subjetivo como consecuencia del desarrollo legislativo o administrativo de las cláusulas constitucionales" (Corte Constitucional, sala quinta de revisión, sentencia T-869, 2006), 
es decir, aquella situación en la que, una vez definidas las políticas públicas de distribución de los recursos, los criterios de asignación, y los requisitos y procedimientos para el reconocimiento de derechos económicos, sociales y culturales, se constituyen derechos subjetivos que pueden ser exigidos en sede de tutela (Corte Constitucional, sala primera de revisión, Sentencia T- 761, 2011)

Ahora bien, en lo que respecta a su procedencia, la jurisprudencia de la Corte Constitucional en sede de tutela ha establecido como requisitos generales de procedencia de la misma el que i) No exista otro medio judicial que permita defender el derecho objeto de amparo, o que existiendo se hayan agotado completamente, salvo aquellos eventos en los cuales se utilice la Tutela como mecanismo de carácter transitorio para la protección del derecho cuya violación es inminente a fin de evitar un daño irreversible (carácter residual). Respecto de esa primera condición de procedibilidad la Corte Constitucional ha expresado de manera reiterativa y tajante que el objetivo de la solicitud de amparo de derechos fundamentales no es remplazar los medios judiciales existentes (Corte Constitucional, sala tercera de revision, sentencia T-001, 1992) pues con ello se pretende evitar entre otras circunstancias, la congestión judicial constitucional, máxime si se tiene en cuenta que al ser un recurso de urgencia, su objeto no es que a través del mismo se eviten los plazos y términos ordinarios de los procesos judiciales.

Sin embargo, dada la connotación e importancia de la protección de los derechos fundamentales también se ha considerado la necesidad de que los medios judiciales existentes, en el evento de que existan, sean efectivos e idóneos para su protección. En efecto como lo manifiesta (Botero Marino, 2009):

Si se comprueba que formalmente existe un medio judicial que pudiera servir para la protección del derecho fundamental pero que desde el punto de vista sustancial el agotamiento de este recurso implica la consumación de un perjuicio iusfundamental irremediable, el amparo constitucional es procedente (pág. 117)

Ello requiere entonces un juez que sea capaz de identificar los eventos en los cuales pese a la existencia de medios judiciales ordinarios, estos por requerir plazos más amplios no resulten ser efectivos ante la posible consumación del perjuicio hacía el derecho fundamental, por lo cual la acción de tutela es adecuada. Por otro lado, la Corte Constitucional 
ha precisado además que, ante la existencia de otro medio judicial la acción de tutela es procedente cuando se utilice como medio transitorio para evitar un perjuicio irremediable, aun si no se ha iniciado el proceso ordinario previsto, siempre y cuando no haya operado la caducidad o no haya fenecido el término para dar inicio al mismo pues si ello así ocurriere entonces seria evidente la inexistencia de un futuro proceso judicial y la tutela no operaria como mecanismo transitorio, con lo cual no concurriría además el requisito de la inmediatez. La anterior regla contiene una única excepción consistente en la imposibilidad absoluta del afectado para proponer en tiempo la acción judicial, casos en los cuales es procedente la acción de tutela.

Un segundo requisito de procedencia de la solicitud de amparo consiste en que el derecho que se invoque como conculcado, no sea de carácter general, impersonal, abstracto, aquellos que salvaguarden intereses públicos o colectivos y que no se pueda salvaguardar con el recurso constitucional del habeas corpus, escapando de la órbita de protección de la tutela el derecho a la libertad personal. En efecto, se requiere que el derecho invocado sea de aquellos llamados fundamentales o que siendo en sus inicios impersonales, abstractos, cuyo contenido no se encuentra desarrollado por las normas vigentes, al ser de carácter prestacional sean acogidos bajo el criterio de la transmutación de derechos, del cual ya nos hemos referido con precedencia. Así mismo, los derechos colectivos no son susceptibles de control de tutela pues la constitución nacional les asignó la acción popular como mecanismo natural de protección.

En tercera medida, para que sea procedente la acción de tutela se requiere además que la violación del derecho no haya ocasionado un daño consumado o que habiéndolo hecho continúen las acciones $\mathrm{u}$ omisiones violatorias del mismo, tal y como se desprende de lo establecido en el artículo octavo del decreto 2591 de 1991. De lo cual se colige que, la amenaza o transgresión del derecho fundamental debe ser actual, permanente en el tiempo de manera que pueda predicarse la inexistencia de un perjuicio irremediable, pues de ser así perdería utilidad la solicitud de amparo.

Ahora bien, oportuno resulta establecer la existencia de requisitos adicionales para la procedencia y/o prosperidad de la acción de tutela, en los eventos de providencias judiciales, es decir, cuando la amenaza o infracción del derecho fundamental emanen de una decisión proferida por un órgano que ostente funciones jurisdiccionales. Para lo cual, si bien 
la Corte Constitucional en su jurisprudencia ha manifestado en primera medida que se trata de una posibilidad excepcional, pues no es "un medio alternativo, ni menos adicional o complementario para alcanzar el fin propuesto. Tampoco puede afirmarse que sea el último recurso al alcance del actor, ya que su naturaleza, según la Constitución, es la de único medio de protección" (Corte Constitucional, sala plena, sentencia C-543 , 1992); También es cierto que, como se analizó en la sentencia T-1031 de 2001, "la acción de tutela procede contra una providencia judicial que omite, sin razón alguna, los precedentes aplicables al caso o cuando "su discrecionalidad interpretativa se desborda en perjuicio de los derechos fundamentales de los asociados" (Corte Constitucional, sala septima de revisión, sentencia T-1031, 2001)

En desarrollo a lo anterior el Tribunal Constitucional, arguyó que además de las condiciones generales de procedencia de la acción de tutela, para los eventos específicos de providencias judiciales es necesario que por un lado se incurra en una de las siguientes causales genéricas de procedencia (noción que remplazo la anterior postura de "vía de hecho" según se instituyó en la sentencia C- 774 de 2004): i) defecto orgánico (falta de competencia del funcionario que dictó la orden judicial), ii) defecto procedimental absoluto (el funcionario no agotó el trámite procesal de conformidad con las normas procesales), iii) defecto material o sustantivo (la decisión es proferida con fundamento en normas inexistentes, que han perdido vigencia, inconstitucionales o impertinentes al caso bajo estudio), iv) defecto factico (inobservancia en el decreto, practica o valoración de las pruebas recaudadas en el proceso, o darle valor a pruebas nulas de pleno derecho o violatoria de derechos fundamentales), v) error inducido (un tercero induce al juez a un error, sobre el cual toma la decisión), vi) decisión sin motivación, vii) desconocimiento del precedente judicial (el juez se aparta del precedente fijado por la Corte Constitucional, por los órganos de cierre de su jurisdicción, o limita los efectos de la sentencias de esas colegiaturas) y viii) violación directa de la constitución (Corte Constitucional, sala tercera de revisión, sentencia T-774, 2004).

Por otro lado se hace igualmente necesario que se cumplan los requisitos formales que son i) que el asunto sea de evidente relevancia constitucional, ii) que se hayan agotado los medios o recursos ordinarios, iii) que se cumpla el requisito de la inmediatez, es decir, que el amparo sea propuesto en un término razonable, sobre lo cual, La Corte Constitucional ha establecido que solo existen tres casos excepcionales en los cuales el 
requisito de la inmediatez puede ceder así: i) Que exista un motivo valido que justifique la inactividad del tutelante como encontrarse en situación de indefensión, abandono, incapacidad física, etc., ii) Que la inactividad injustificada vulnere el núcleo esencial de derechos fundamentales de terceros que puedan verse afectados con la decisión, iii) Que exista una relación entre la inactividad y la afectación a los derechos de los interesados, iv) Que se demuestre que la afectación perdura en el tiempo y que pese a que el hecho que la originó es antiguo la situación desfavorable continua (Corte Constitucional, sala octava de revision, sentencia T- 246, 2015), iv) que la irregularidad presentada en el proceso destelle a la sentencia y vulnere derechos fundamentales de la parte tutelante, v) que se identifiquen los hechos que generaron la infracción a los derechos fundamentales y sean expuestos en los recursos ordinarios cuando ello fuera posible y finalmente, vi) que la providencia judicial demandada en tutela no sea un fallo de tutela (Corte Constitucional, sala plena, sentencia C-590, 2005).

Ultimo evento que si bien en sus inicios constituía un criterio unificado y pacifico respecto de su imposibilidad, en la actualidad ello no es del todo así, pues el Máximo órgano de la jurisdicción constitucional en su evolución jurisprudencial ha admitido la posibilidad de que en los casos de cosa juzgada fraudulenta se pueda interponer de manera excepcional acción de tutela en contra de un fallo de tutela. En sumo, para concluir con lo descrito en este capítulo se tiene que la acción de tutela como mecanismo relevante en el Estado social de derecho colombiano, permite proteger de manera sumaria y por lo tanto expedita, derechos fundamentales nominados, innominados, por conexidad y transmutación. Se trata de un mecanismo que en Colombia tiene naturaleza de proceso judicial autónomo, sumarial, preferente, informal y residual. De manera general procede cuando no se cuenten con otros mecanismos ordinarios de protección o cuando existiendo los mismos no sean efectivos o idóneos, o se utilice la tutela como mecanismo transitorio para prevenir un perjuicio irremediable; cuando no se trate de derechos impersonales, colectivos o protegidos por el habeas corpus y cuando la amenaza no se haya consolidado a tal punto que se trate de un daño consumado salvo si aún subsiste la acción u omisión que generó la amenaza. Puede ser interpuesta en contra de autoridades o particulares cuando en uno $u$ otro caso se vulnere un derecho fundamental; entre esas autoridades se encuentran aquellas que ejercen funciones jurisdiccionales, cuyas decisiones la Corte Constitucional en el 
estado actual de su evolución jurisprudencial, ha aceptado la posibilidad de procedencia de la acción de tutela cuando se advierta la ocurrencia de una vía de hecho, hoy denominada causal genéricas de procedencia; teniendo que cumplir además con los requisitos formales dentro de los cuales esta que el fallo demandado no sea de tutela.

\section{Evolución histórica en la jurisprudencia de la Corte Constitucional respecto de la procedencia de la acción de tutela en contra de una sentencia de tutela}

El propósito de este capítulo es examinar las posturas jurisprudenciales que en esta materia ha estipulado el Tribunal constitucional, analizando los argumentos y escenarios jurídicos plasmados concretamente en las sentencias SU-1219 de 2001 y la SU-627 de 2015, las cuales fueron seleccionadas para su análisis en vista de que las mismas fueron expedidas con el propósito de unificar los criterios jurisprudenciales frente al tema en dos escenarios temporales distintos.

\section{Primera etapa:}

En el estudio jurisprudencial de la Corte Constitucional de Colombia respecto de la procedibilidad de "la tutela en contra de tutela" es posible identificar un primer escenario caracterizado por la prohibición expresa de esa noción. La misma fue recogida en la sentencia SU-1219 de 2001 en donde la misma corporación seleccionó para efectos de revisión dos procesos de tutela, Expediente No. T-412756 de la Caja de Compensación Familiar de Cartagena contra el Juzgado Primero Civil del Circuito de Cartagena y el No. T-412756 inicialmente no seleccionado para surtir el grado de revisión (Corte Constitucional, sala plena, sentencia SU-1219, 2001), y acumularlos por unidad de materia. En esa oportunidad luego de revisar las circunstancias fácticas que fundamentaron la acción, la Corte se planteó como problema jurídico: ¿Puede interponerse una acción de tutela contra una sentencia de tutela, alegando que se ha incurrido en una vía de hecho? (Corte Constitucional, sala plena, sentencia SU-1219, 2001)

Para lo cual consideró en primera medida la alta posibilidad de que los falladores al no ser infalibles en sus decisiones puedan cometer errores y ser susceptibles de reclamación por parte de los ciudadanos en atención a la eventual vulneración de un derecho. Situación de la cual es común en los juzgadores ordinarios y los que revisten la toga de juez constitucional. Sin embargo, precisó que entre uno y otro existen diferencias en lo que respecta al procedimiento, así como del consecuente trámite que para efectos de subsanar esos errores puedan 
preverse que justifican la existencia de mecanismos disimiles para esos efectos.

Así, los juzgadores de casos ordinarios en obediencia a la ley y en interpretación a la misma pueden cometer errores que generen violaciones a derechos fundamentales con lo cual pueden incurrir en vías de hecho que son, tal como hasta este punto lo ha aceptado la jurisprudencia constitucional, susceptibles de la acción de tutela en atención no solo a la protección del titular del derecho, sino además que los preceptos legales y las órdenes judiciales acompasen con los fines y propósitos constitucionales, puesto que "el ordenamiento jurídico es uno sólo y la legislación debe interpretarse y aplicarse de conformidad con la Constitución" (Corte Constitucional, sala plena, sentencia SU-1219, 2001).

Empero considera que, en el caso de los procesos de tutela es distinto puesto que el juez constitucional con el fin de salvaguardar el derecho fundamental aplica de manera directa el texto superior de ahí a que pueda resaltarse la característica de especificidad de la tutela, según la cual se resuelve el caso objeto de la solicitud de amparo solo en atención a los preceptos consagrados en la carta magna y no en la ley sin que se considere de manera irrelevante lo dicho en ella. Tal como se dijo anteriormente la Corte creyó que, los jueces de tutela no escapan de la eventualidad de equivocarse en sus decisiones e incurrir en una vía de hecho; en el cual el ciudadano no queda afectado pues para esos eventos la constitución y la ley establecieron la impugnación del fallo y su inminente revisión en cabeza de la Corte Constitucional, en los términos del artículo 86 del texto superior.

Según el alto juez constitucional, la revisión es un mecanismo diseñado no solo para "controlar las sentencias de tutela de los jueces constitucionales que conocen y deciden sobre las acciones de tutela" (Corte Constitucional, sala plena, sentencia SU-1219, 2001) sino además para "unificar la interpretación constitucional en materia de derechos fundamentales" (Corte Constitucional, sala plena, sentencia SU-1219, 2001) y "erigir a la Corte Constitucional como máximo tribunal de derechos constitucionales y como órgano de cierre de las controversias sobre el alcance de los mismos" (Corte Constitucional, sala plena, sentencia SU$1219,2001)$. Expreso que, la Constitución política excluyó la posibilidad de que en contra de un fallo de tutela se interpusiera una tutela alegando una eventual vía de hecho, porque fue propósito del constituyente crear un mecanismo cuyas etapas estuviesen claramente estipuladas; en el 
cual, previendo los posibles errores, existiese un recurso propio para su corrección denominado recurso de revisión, agotado por un órgano de rango superior, cual es la Corte Constitucional.

Tal como queda claro del contenido del artículo 40 del decreto 2591 de 1991 no fue en principio propósito del legislador la procedencia del recurso de amparo contra fallos de esa misma naturaleza. Esbozo la Corte Constitucional que ello es posiblemente con el fin de evitar que los conflictos resueltos en sede de tutela puedan prolongarse de manera indefinida en el tiempo conculcando la seguridad jurídica y rebosando el principio primordial de la acción de tutela cual es la protección de los derechos fundamentales de manera cierta, rápida y efectiva. Resaltó el Tribunal Magno las virtudes del recurso de revisión, el cual fue estipulado como un medio para que esa misma corporación como guardiana de la constitución realizara control de las posibles vías de hecho que pudiesen suscitarse en los fallos de tutela, constituyéndose en el cierre de las circunstancias jurídicas que se dilucidan en los procesos de amparo. Por ello resaltó que en lo que respecta a la revisión son relevantes los siguientes aspectos.

En primera medida, en virtud de los consagrado en los artículos 86 de la constitución política y 31 del decreto 2591 de 1991, los jueces constitucionales tienen el deber de remitir a la Corte Constitucional los fallos de tutela, ello con el fin de que sea un órgano centralizado encargado de la interpretación constitucional el que determine cuales casos representan cierto grado de relevancia en torno a un tema específico para efectos de unificación jurisprudencial (Corte Constitucional, sala plena, sentencia SU-1219, 2001). Así mismo, con el objeto de evitar que los derechos fundamentales no obtengan una efectiva protección, la Corte Constitucional realiza un ejercicio de verificación de todas las sentencias de tutela que llegan a esa instancia a fin de determinar cuáles son las que deben ser revisadas y cuales no ameritan ese ejercicio, teniendo en todo caso que, estudiar el fallo remitido y adoptar una decisión. En este proceso, vale la pena resaltar que cualquiera de las partes o el defensor del pueblo, puede solicitar que un determinado fallo sea escogido por relevancia constitucional, o porque a su parecer se ha cometido un error que no representa tal gravedad para ser considerado vía de hecho (Corte Constitucional, sala plena, sentencia SU-1219, 2001).

Ahora bien, en segunda medida, los efectos de las sentencias que no son escogidas para su eventual revisión son aquellos propios de la cosa juzgada constitucional pues la decisión emitida por la Corte de no 
revisar un fallo genera la ejecutoria formal y material de la sentencia, siendo esos efectos inevitables. Ello obedece a la necesidad de asegurar un ambiente de seguridad jurídica y legitimar al Tribunal Constitucional como verdadero órgano de cierre de esa jurisdicción.

En tercera medida, la Corporación Constitucional manifiesta que el ejercicio realizado en sede de revisión de una sentencia seleccionada es mucho más amplio de aquel eventualmente realizado respecto de una vía de hecho, ya que cuando la misma examina los fallos allegados no solo lo hace para efectos de unificación jurisprudencial de temas relevantes para la interpretación constitucional, sino además como método de control de legalidad ante la posible existencia de una vía de hecho que releva su escogencia.

Con todos esos argumentos se llega a una primera conclusión consistente en la constitución de la revisión, como un mecanismo efectivo e idóneo para la salvaguarda de los derechos fundamentales ventilados en los fallos de tutela expedidos por todos los jueces constitucionales del país. Así mismo, en concordancia a lo anterior se arriba a una segunda conclusión: no son procedentes las acciones de tutela en contra de los fallos de tutela por la existencia de vías de hecho, ya que ello resultaría inocuo ante la existencia de la revisión como un instrumento regulado por la ley, autorizado por la constitución, útil para esos efectos.

Por otro lado, para reforzar esa interpretación la Corte examina los efectos de la cosa juzgada ordinaria y constitucional. En lo tocante a la primera de ellas es viable que ante la existencia de una vía de hecho, proceda la acción de tutela para salvaguardar derechos como el debido proceso. Referente a la segunda, esa posibilidad se encuentra hasta este momento descartada, teniendo en cuenta que ante un vicio de esa magnitud se cuenta con el recurso de revisión y el de insistencia para que sea escogido para la misma, fenecido el cual, la sentencia se torna inmodificable. Tal como se ha dicho anteriormente cuando la Corte Constitucional decide no escoger un fallo para revisión el mismo adquiere ejecutoria material con efectos de cosa juzgada constitucional; misma situación acontece respecto de aquellos fallos escogidos para revisión y en los cuales la Corte ha emitido una decisión o cuando no siendo escogido el plazo para insistir en su escogencia ha fenecido. En estos casos no hay lugar a reabrir un proceso que ha sido legalmente decidido y concluido. En esa medida,

Admitir que los fallos de tutela definitivamente decididos o excluidos para revisión sean luego objeto de una nueva 
acción de tutela, sería como instituir un recurso adicional ante la Corte Constitucional para la insistencia en la revisión de un proceso de tutela ya concluido, lo cual es contrario a la Constitución (Corte Constitucional, sala plena, sentencia SU1219, 2001).

Si bien es cierto que la protección de los derechos fundamentales pugna con la seguridad jurídica al estudiar la admisión de la tutela sobre tutela, la Corte considera que la tensión se supera al estudiar el hecho de que ambas causas confluyen en un mismo sentido pues si un fallo de tutela no fuese estable también se cercenarían los derechos fundamentales de las partes al estar sometido a la eventualidad de que el conflicto no finiquitara nunca, desnaturalizando el propósito que quiso darle el constituyente.

Esa restricción encuentra su justificación esencialmente en dos argumentos. El primero de ellos gira en torno a la seguridad judicial, la protección del acceso efectivo a la administración de justicia y la efectividad material de la acción de tutela que se verían mermados ante la posibilidad de interponer contra una situación jurídica consolidada demandas sobre demandas, lo cual haría interminable las discusiones judiciales.

El segundo de ellos observa que, en el caso de las tutelas ya existe un instrumento eficaz para detectar y corregir las posibles vías de hecho existentes en los fallos de esta naturaleza ante un órgano de cierre con mayor especialidad que tiene como función expresa la custodia de la constitución. Ponderó la alta corporación, la eventualidad de que en un error de selección para revisión no se escogiera una sentencia con una verdadera vía de hecho, lo cual sería nocivo para las garantías constitucionales; pero al respecto dijo que esa posibilidad es excepcional y proporcionadamente menor a la afectación de derechos, la perdida de efectividad del mecanismo del amparo que nunca tendría estabilidad y consolidación, si se aceptara la tutela contra tutela que se convertiría en una práctica permanente (Corte Constitucional, sala plena, sentencia SU-1219, 2001).

\section{Segunda etapa}

Una segunda etapa está constituida por el cambio de posición frente a la procedencia de la tutela en contra de fallos de tutela, postura que se consolidó con la sentencia SU- 627 de 2015, posición que se mantiene en la actualidad. 
Para esa decisión la Corporación previa insistencia de una Magistratura de la Corte, que consideró la relevancia constitucional del tema, seleccionó para efectos de revisión un proceso de tutela, Expediente No. T- 4.496.402 de la Dirección Nacional de Estupefacientes en liquidación contra el Juzgados Primero Promiscuo Municipal y Promiscuo del Circuito de Pivijay (Magdalena en el que se solicitaba el amparo de los derechos fundamentales al debido proceso, defensa y acceso a la administración de justicia que se consideraban estaban siendo infringidos por los Juzgados Primero Promiscuo Municipal y Promiscuo del Circuito de Pivijay en Magdalena al incurrir en una posible vía de hecho en la sentencia de tutela demandada.

Los argumentos de insistencia del Magistrado Jorge Pretelt Chaljub giraron en torno a lo siguiente:

1. Una de las causales de procedencia de la acción de tutela en contra de las providencias judiciales es que la misma sentencia objetada no sea de tutela, circunstancia que en ese caso no se respetaba pues los jueces de instancia decidieron una tutela sobre otra tutela.

2. De conformidad con la jurisprudencia consolidada hasta esa época, específicamente los postulados de la SU- 1219 de 2001, uno de los efectos de las sentencias no escogidas para revisión es la configuración de la cosa juzgada constitucional; efecto que se predicaba respecto de la sentencia de tutela demandada que no había sido seleccionada por la Corte y cuya situación no fue respetada por el juez de instancia.

3. De conformidad con la sentencia T-218 de 2012, existe una excepción a la cosa juzgada referente a cuando se ha cometido fraude o se ha probado la ilegalidad en la actuación, situación que debe ser conocida necesariamente por la Corte Constitucional. Arguyo que esa corporación era "la llamada a determinar si se presentaron estas excepcionales circunstancias y no dejar esta tarea a los jueces de instancia, pues se pueden llegar a generar decisiones contradictorias que terminen en un desconocimiento masivo de la cosa juzgada constitucional" (Corte Constitucional, sala plena, sentencia SU- 627, 2015)

4. Esta sería una oportunidad para esa corporación de unificar jurisprudencia frente al tema de la procedencia de la acción de tutela en contra de fallos de tutela con posterioridad al 
pronunciamiento realizado en la Sentencia T- 218 de 2012, en donde se admitieron los casos de fraude en la actuación como excepción a la regla dada en la sentencia SU- 1219 de 2001.

Las circunstancias fácticas relevantes para tomar la decisión y unificar criterios consistieron en primera medida en el conocimiento por parte de un juez de instancia, Tribunal superior de distrito judicial del Magdalena, de una acción de tutela en contra de un fallo de tutela proferida por los jueces de Pivijay cuyo trámite se había agotado en vulneración del derecho al debido proceso, al no vincular a una parte interesada en los efectos de la sentencia al proceso. Vale la pena notar que, en el estudio del caso, el juez no analizó la sentencia de tutela en sí misma, sino que procedió con el estudio de legalidad de su trámite constatando que, efectivamente en el transcurso del procedimiento adelantado de la acción de tutela que se demandaba, por un lado, no se integró en debida forma el contradictorio al no citar a terceros que podrían verse afectados con las resultas de la sentencia, eventualidad que sucedió; y por otro lado, la misma fue decidida por un funcionario que carecía de competencia.

De esas circunstancias la Corte notó que el examen sobre el fallo de tutela, no se refirió a la existencia de algún defecto en si misma sino en los vicios acaecidos con anterioridad a la expedición de la sentencia. Ello resulta importante pues según la línea jurisprudencial que en torno al tema ha planteado la Corte Constitucional, iniciada con la sentencia SU-1219 de 2001, no es procedente la acción de tutela en contra de un fallo de tutela. Postura que ha sido utilizada por la Corporación para fallar los siguientes asuntos:

Las Sentencias T-021, T-174, T-192, T-217, T-354, T-444, T-623 y T-625 de 2002; T-200, T-502 y T-1028 de 2003; T-528 de 2004; T-368 y T-944 de 2005; T-059 y T-237 de 2006; T-104 de 2007; T-1208 de 2008; T-282 de 2009; T-041, T-137, T-151 y T-813 de 2010; T-474 y T-701 de 2011; T-208 de 2013 (Corte Constitucional, sala plena, sentencia SU- 627, 2015)

De los cuales, en algunos se extrajeron reglas importantes al caso que se sustraen en esencia a la procedencia de la acción de tutela en contra de los procedimientos anteriores al fallo de tutela o posteriores a ella. Reglas que se resumen en lo siguiente: I) La tutela en contra de tutela es en principio improcedente salvo cuando se invoquen actuaciones irregulares que no fueran advertidas por la Corte Constitucional en sede de revisión (Corte Constitucional, sala octava de revisión, sentencia T- 623, 
2002), II) Es posible presentar tutelas en contra de incidentes de desacato (Corte Constitucional, sala novena de revisión, sentencia T- 368, 2005), III) Es posible interponer incidentes de nulidad en contra de las sentencias proferidas por la Corte Constitucional cuando se esté en presencia de vicios que afecten el debido proceso, de manera excepcional y restrictiva (Corte Constitucional, sala cuarta de revisión, sentencia T- 282, 2009), IV) Se pueden interponer acciones de tutela cuando se adviertan actuaciones fraudulentas no en contra de la sentencia de tutela, sino en una actuación de trámite de la misma o en el de incidente de desacato (Corte Constitucional, sala primera de revisión, sentencia T-474, 2011)

Sin embargo, fue la sentencia T- 218 de 2012 en donde la Corte Constitucional refirió a la cosa juzgada fraudulenta, entendida como aquella que citando a (Véscovi, 2006, pág. 253) "se predica de un proceso que ha cumplido formalmente con todos los requisitos procesales y que materializa en esencia un negocio fraudulento a través de medios procesales, que implica un perjuicio ilícito a terceros y a la comunidad" (Corte Constitucional, sala novena de revisión, sentencia T-951, 2013); como la única excepción a la postura existente sobre el tema reconociendo que, la cosa juzgada no puede ser absoluta sino que la misma debe ceder ante el evento de fraus omnia corrumpit, El fraude lo corrompe todo (Corte Constitucional, sala plena, sentencia SU- 627, 2015) pues en estos casos al entrar en conflicto con la justicia material, debe permanecer ésta última máxime si el fraude ha sido cometido por el mismo juez.

Esa posición fue utilizada en las sentencias T- 951 de 2013 y T-373 de 2014 en donde el Máximo órgano de la jurisdicción constitucional expuso como argumentos que "la cosa juzgada, incluso la constitucional, "no es un fin en sí mismo, sino un medio para alcanzar el valor de la justicia" (Corte Constitucional, sala novena de revisión, sentencia T-951, 2013) por lo que no debe permitirse "que se consoliden situaciones espurias, Entiéndase como situaciones ilegales, fraudulentas, carentes de autenticidad, bajo el argumento de la obediencia ciega a las situaciones juzgadas, cuando las mismas son producto de la cosa juzgada fraudulenta" (Corte Constitucional, sala novena de revisión, sentencia T-951, 2013). En esa misma jurisprudencia se fijaron reglas de procedencia de la tutela en esos casos, las cuales serán estudiadas en capítulos posteriores. Así mismo recordó la postura adoptada en la sentencia T-272 de 2014 en donde se sostuvo como opción a "la tutela contra tutela" la modulación de los efectos de las sentencias de la Corte 
Constitucional en situaciones fraudulentas o irregulares con el fin de proteger los derechos fundamentales.

Ahora bien, por otro lado, las nociones centrales de procedencia de la acción de tutela no excluyen las actuaciones previas a la sentencia y posteriores a la misma, pues como ha quedado claro la única excepción a la revisión del fallo de tutela en sí misma es cuando se advierta fraude (cosa juzgada fraudulenta). En efecto, la Corte examinó como en anteriores oportunidades se habían protegido los derechos fundamentales al debido proceso cuando había sido violentado en el trámite de la acción constitucional, pues las actuaciones arbitrarias de los jueces de tutela si son susceptibles de la misma. Por ejemplo, en sentencia T-162 de 1997 se evaluó la posibilidad de que el auto que niega la impugnación del fallo de tutela pueda ser objeto de esta misma acción; examen que arrojó un resultado positivo. Empero no es procedente respecto de pretender el cumplimiento de una sentencia de tutela pues para esos casos el legislador ha provisto al incidente de desacato, en el que debe respetarse el debido proceso que puede ser protegido a través del recurso de amparo.

Para concluir con todo lo descrito en este capítulo, ttal como ha quedado claro, la Corte Constitucional al fijar las reglas formales de procedencia de la solicitud de amparo en contra de providencias judiciales, ha prohibido de manera expresa que sobre un fallo de tutela pueda proceder otra acción de tutela. Frente a ese tema, si bien es cierto la Corte en sus inicios se mantuvo renuente en aceptar esa posibilidad, en la actualidad su pronunciamiento es diferente al permitir la tutela contra tutela de manera excepcional cuando se advierta la cosa juzgada fraudulenta, en cumplimiento de ciertos requisitos y sobre las actuaciones propias del trámite tutelar.

\section{La procedencia excepcional de la acción de tutela en contra de fallos de tutela: pautas emanadas de la sentencia SU- 627 de 2015, proferida por la Corte Constitucional}

El objeto de este capítulo es describir las condiciones de procedencia de acción de tutela de conformidad con lo dicho en las sentencias T-218 de 2013, que aceptó a la cosa juzgada fraudulenta como excepción al criterio general de improcedencia de tutela sobre sentencia de tutela en sí misma y la SU-627 de 2015, que lo acogió adicionando además la posibilidad 
de tutelar también las actuaciones irregulares que vulneraran el debido proceso antes y después de dictada la misma.

Ante estas circunstancias el ejercicio primario debe ir encaminado a identificar si la tutela se "dirige contra la sentencia proferida dentro de él o contra una actuación previa o posterior a ella" (Corte Constitucional, sala plena, sentencia SU- 627, 2015).

\section{Cuando se trata de amparar derechos conculcados por una sentencia de tutela: casos de "fraus omnia corrumpit"}

Por un lado, en lo que respecta a la interposición de la solicitud de amparo en contra de una sentencia de esa misma naturaleza, como ha quedado precisado, la regla general es que no procede, máxime si la sentencia ha sido expedida por la Corte Constitucional en sala plena o en alguna de sus salas de revisión, caso en el cual solo es susceptible de nulidad ante esa misma corporación agotado las normas existentes en el decreto 2591 de 1991, Artículo 49 del decreto 2067 de 1991.

Sólo es posible cuando la sentencia haya sido expedida por juez constitucional diferente a la Corte y cuando se advierta fraude en sí misma. Para estas circunstancias, deben cumplirse además de los requisitos generales de procedencia de la acción de tutela, los propios del amparo dirigido hacia providencias judiciales y los de la sentencia T-951 de 2013 que frente al tema específico que aquí se habla, estableció que debe cumplirse:

a) La acción de tutela presentada no comparte identidad procesal con la solicitud de amparo cuestionada, es decir, que no se está en presencia del fenómeno de cosa juzgada (Corte Constitucional, sala novena de revisión, sentencia T-951, 2013).

b) Debe probarse de manera clara y suficiente, que la decisión adoptada en una anterior acción de tutela fue producto de una situación de fraude, que atenta contra el ideal de justicia presente en el derecho (Fraus omnia corrumpit) (Corte Constitucional, sala novena de revisión, sentencia T-951, 2013).

c) No existe otro mecanismo legal para resolver tal situación, esto es, que tiene un carácter residual (Corte Constitucional, sala novena de revisión, sentencia T-951, 2013) 


\section{Cuando se trata de amparar derechos conculcados en la actuación surtidas en el trámite de la acción de tutela}

Para lo cual es relevante identificar si la actuación fue con anterioridad o con posterioridad a la expedición de la sentencia. Si es con anterioridad y el vicio que genera la infracción consiste en el deber de notificar o vincular a un tercero interesado en las resultas del proceso, si procede la acción de tutela, teniendo que cumplirse además los requisitos generales de su procedencia. Ello si la Corte seleccionó el caso o no (Corte Constitucional, sala plena, sentencia SU- 627, 2015).

Por el contrario, si el vicio que genera la infracción al derecho fundamental sucede con posterioridad a la expedición de la sentencia y se trata de lograr el cumplimiento de esta, no es procedente la acción, pues para esos efectos existe el incidente de desacato. La excepción a esta regla se configura cuando en el trámite del incidente se vulnera un derecho fundamental, evento en el cual si es procedente, teniéndose que cumplir los requisitos generales de procedencia de la acción de tutela y los específicos contra providencias judiciales (Corte Constitucional, sala plena, sentencia SU- 627, 2015).

\section{Análisis crítico de la postura jurisprudencial adoptada por el Máximo órgano de la jurisdicción constitucional frente al tema planteado}

Se pretende finalmente en este acápite exponer una postura crítica frente a la posición actual de la Corte Constitucional respecto de la procedencia excepcional de la acción de tutela en contra de un fallo de tutela. Para satisfacerlo primero nos referiremos a la posición de manera general, luego a las causales específicas de procedibilidad y si las mismas a nuestro juicio son efectivas y finalmente a la perspectiva futura del tema. Considerar la procedencia de la acción de tutela en contra de un fallo de tutela representa sin lugar a duda una innovación jurisprudencial relativamente beneficiosa para los derechos de las partes que integran los procesos constitucionales de esta naturaleza, especialmente para el derecho al debido proceso que regularmente es el que se encuentra en la mayoría de los casos conculcado cuando se trata de providencias judiciales.

Ello se considera así porque tal como lo expuso la Corte en la sentencia T-218 de 2012, la cosa juzgada al igual que ciertas libertades no es absoluta, sino que debe tener excepciones. Si bien es cierto es razonable que se impida que los procesos judiciales sean interminables, resultado que sería el esperable de permitirse en todos los casos la tutela contra tutela, a fin de proteger la seguridad jurídica y el acceso 
a la administración de justicia de los ciudadanos; también es cierto que ese fin puede alcanzarse si se permite cohabitar la posibilidad de la procedencia excepcional de la misma medida, para salvaguardar derechos constitucionales como el debido proceso.

Adicionalmente ha de considerarse que el juzgador es una persona humana que puede equivocarse en el trámite de las acciones ordinarias, así como el trámite de las acciones de tutela, por diversas razones entre ellas la celeridad que caracteriza a la misma y la existencia de términos cortos y perentorios que en algunos casos complejos no son suficientes para fallar un caso sin que haya lugar a dudas de cualquier naturaleza. Ello no es predicable de todos los casos, pero es una posibilidad que debe considerarse.

Téngase en cuenta además que, en muchas ocasiones los jueces no pueden vislumbrar todas las circunstancias fácticas que rodean una situación en particular, dada a la condición actual de la congestión en la administración de justicia, la demora en la consecución de la prueba cuando es de difícil consecución, que en algunos eventos cede ante la celeridad y los términos cortos con los que cuentan los jueces para fallar una tutela. En estos casos, es posible que el juez cometa errores de derecho que se traduzcan en una cosa juzgada fraudulenta que afecte intereses de terceros interesados en el proceso. Esa equivocación en un fallo de tutela que puede generar fraude o afectación grave a los derechos de una parte vinculada o no al proceso, no solo puede ser cometida por un juez de instancia de menor jerarquía sino que además puede serlo respecto de un juez de mayor especialidad integrante de un órgano colegiado como la misma Corte Constitucional, razón por la cual no se comprende la renuencia del mismo órgano de prever en su jurisprudencia una excepción a la regla de improcedencia de la tutela sobre tutela dictada por esa corporación. Recuérdese que si procede el amparo solo de sentencias no proferidas por la Corte Constitucional de conformidad con los parámetros del fallo SU-627 de 2015 (Corte Constitucional, sala plena, sentencia SU- 627, 2015). Si lo que se trata es de proteger los derechos al debido proceso cuando sucedan casos de Fraus omnia corrumpit no debe admitir discriminación si la sentencia que contiene el fraude procede del máximo órgano o de un juez de instancia, para proceder con su revisión.

Aunado a lo anterior, ha de indicarse que de acuerdo con los argumentos esgrimidos por la Corte Constitucional en la sentencia SU1219 de 2001 (jurisprudencia que establece la improcedencia de la tutela 
contra tutela de manera general) la parte que crea afectado su derecho al debido proceso u otra garantía constitucional con ocasión a un fallo de tutela que ha surtido efectos de cosa juzgada constitucional por ser seleccionado para revisión por ese mismo órgano no puede intentar una nueva acción de tutela pues cuenta con la posibilidad de solicitar la nulidad en los términos del artículo 49 del decreto 2067 de 1991, el cual reza:

Artículo 49. Contra las sentencias de la Corte Constitucional no procede recurso alguno.

La nulidad de los procesos ante la Corte Constitucional sólo podrá ser alegada antes de proferido el fallo. Sólo las irregularidades que impliquen violación del debido proceso podrán servir de base para que el Pleno de la Corte anule el Proceso (Decreto 2067, 1991).

Nótese que ineficiente sería la opción dada por el máximo órgano constitucional pues la misma solo permitiría declarar nula la actuación y no el fallo en sí mismo, pues la norma es clara cuando establece que la nulidad solo puede alegarse antes del fallo. Diferente sería si, advertido el vicio que afecta el debido proceso se propusiera el incidente de nulidad a fin de evitar una sentencia fraudulenta, caso en el cual ese mecanismo sería adecuado. Con todo escapan de esa posibilidad los fallos en los cuales ninguna de las partes o incluso el mismo órgano judicial se hayan manifestado respecto de algún error que termina siendo notable con los efectos prácticos del fallo judicial y de afectación grave sobre intereses constitucionales de una comunidad o un tercero. Para estos eventos, tal como se encuentra planteada la postura jurisprudencial frente al tema, la tutela no procedería la misma afectándose derechos fundamentales.

Ahora bien, importante resulta advertir que la posición actual de la Corte Constitucional amerita jueces capacitados y activos que sean capaces de identificar una posible cosa juzgada fraudulenta en una sentencia de tutela que sea presentada para su conocimiento, a fin de que por un lado no se declare improcedente de plano y se evite darle de uso a esa posición cuando se amerite; por otro lado evitar que la administración de justicia en sede de tutela se llene de procesos judiciales cuyas pretensiones en el trasfondo lo que persigan sea una nueva instancia para la revisión del asunto jurídico resuelto en la sentencia de tutela cuestionada. 
Finalmente, respecto de la procedencia del amparo frente a actuaciones anteriores o posteriores al fallo de tutela, la misma representa una idea útil puesto que no en todos los casos los tutelantes arguyen afectación a derechos fundamentales por la tutela en si misma sino respecto de procedimientos anteriores o posteriores que en nada afectan los propósitos de la cosa juzgada constitucional sino que son viables en atención a que esas decisiones son providencias judiciales que sin discusión alguna pueden ser objeto de tutela.

\section{Conclusiones}

Frente al problema planteado ante la procedencia la acción de tutela contra sentencias de tutela de conformidad con la sentencia su- 627 del 2015 de la corte constitucional de Colombia, se ha logrado establecer que la acción de tutela como mecanismo relevante en el Estado social de derecho colombiano, permite proteger de manera sumaria y por lo tanto expedita, derechos fundamentales nominados, innominados, por conexidad y transmutación. Se trata de un mecanismo autónomo, sumarial, preferente, informal y residual. Procede cuando no se cuenten con otros mecanismos ordinarios de protección o cuando existiendo los mismos no sean efectivos o idóneos, o se utilice la tutela como mecanismo transitorio para prevenir un perjuicio irremediable; cuando no se trate de derechos impersonales, colectivos o protegidos por el habeas corpus y cuando la amenaza no se haya consolidado a tal punto que se trate de un daño consumado salvo si aún subsiste la acción u omisión que generó la amenaza. Puede ser interpuesta en contra de autoridades o particulares cuando en uno u otro caso se vulnere un derecho fundamental; entre esas autoridades se encuentran aquellas que ejercen funciones jurisdiccionales, cuyas decisiones la Corte Constitucional en el estado actual de su evolución jurisprudencial, ha aceptado la posibilidad de procedencia de la acción de tutela cuando se advierta la ocurrencia de una vía de hecho, hoy denominada causal genéricas de procedencia; teniendo que cumplir además con los requisitos formales dentro de los cuales esta que el fallo demandado no sea de tutela.

La procedencia de la acción de tutela en contra de un fallo de Tutela no ha sido un tema pacifico en la historia jurisprudencial de la Corte Constitucional. En un primer momento esa corporación por medio de la sentencia SU 1219 de 2001 fijo un criterio de improcedencia expresa de la acción de tutela en contra de un fallo de tutela asegurando que esa posibilidad era nula por los efectos de la cosa juzgada constitucional y la 
existencia de otros mecanismos que podían proteger el debido proceso como la revisión y la nulidad. Posteriormente con la expedición de las sentencias T-218 de 2013 y SU 627 de 2015, la Corte admitió que la cosa juzgada constitucional no era absoluta y debía ceder ante los eventos de violaciones graves al debido proceso y las derivadas de la cosa juzgada fraudulenta cuando ella se advirtiera en el fallo de tutela demandado. Así fijó reglas formales de procedencia excepcional de la solicitud de amparo en contra de providencias judiciales de tutela, cuando se advierta la cosa juzgada fraudulenta, en cumplimiento de ciertos requisitos y sobre las actuaciones propias del trámite tutelar.

De acuerdo con las pautas dadas por la Corte Constitucional en la sentencia SU- 627 del 2015, para determinar si procede excepcionalmente la acción de tutela contra una sentencia de tutela, es necesario identificar si el amparo va dirigido a una sentencia como tal o a una actuación anterior o posterior a ella. Para el primer evento estableció que por regla general no procede máxime si el fallo es expedido por la Corte Constitucional, pero si es expedido por un juez de menor jerarquía y se advierte fraus omnia corrumpit entonces es procedente demostrando que i) El amparo no comparte identidad procesal con el amparo demandado, ii) El fraude cometido, ii) Que no existe otro mecanismo para solucionar la situación. Para el segundo evento, si el vicio que genera la infracción es con anterioridad y consiste en el deber de notificar o vincular a un tercero interesado en las resultas del proceso, si procede la acción de tutela, teniendo que cumplirse además los requisitos generales de su procedencia; ahora si es posterioridad, y se trata de lograr el cumplimiento del fallo, no es procedente la acción. La excepción a esta regla se configura cuando en el trámite del incidente se vulnera un derecho fundamental, evento en el cual si es procedente.

La posición actual adoptada por el Máximo Tribunal Constitucional frente a la procedencia de la acción de tutela contra sentencias de tutela, sin lugar a duda es una innovación jurisprudencial relativamente beneficiosa para los derechos de las partes que integran los procesos constitucionales de esta naturaleza, especialmente para el derecho al debido proceso cuando se advierta errores que generen fraudes o afectación grave a los derechos de una parte vinculada o no al proceso. Sin embargo, consideramos, que el error, no solo puede ser cometido por un juez de instancia de menor jerarquía, sino que además puede serlo respecto de un juez de mayor especialidad integrante de un 
órgano colegiado como la misma Corte Constitucional, razón por la cual no es comprensible la renuencia del mismo órgano de prever en su jurisprudencia una excepción a la regla de improcedencia de la tutela sobre tutela dictada por esa corporación. Si lo que se trata es de proteger los derechos al debido proceso cuando sucedan casos de Fraus omnia corrumpit no debe admitir discriminación si la sentencia que contiene el fraude procede del máximo órgano o de un juez de instancia, para proceder con su revisión. Adicionalmente, nótese además que la alternativa de la nulidad de las sentencias proferidas por ese órgano es ineficiente pues la misma solo permitiría declarar nula la actuación y no el fallo en sí mismo.

\section{Referencias}

Botero Marino, C. (2009). La acción de tutela en el ordenamiento constitucional colombiano. Bogotá D.C., Colombia: Escuela judicial "Rodrigo Lara Bonilla”. Obtenido de http://www.ejrlb.net/biblioteca2011/ content/pdf/a6/10.pdf

Carrera Silva, L. (enero/junio de 2011). La acción de tutela en Colombia. Revista IUS, 5(27), 72-94. Obtenido de http://www.scielo.org.mx/scielo.php?script=sci_arttext\&pid=S1870-21472011000100005\#nota

Constitución Política de Colombia. (1991). [Const.]. Obtenido de http:// www.alcaldiabogota.gov.co/sisjur/normas/Normal.jsp?i=4125

Corte Constitucional, sala cuarta de revisión, sentencia T- 282, [Magistrado ponente: Gabriel Eduardo Mendoza Martelo] (20 de abril de 2009).

Corte Constitucional, sala novena de revisión, sentencia T- 368, [Magistrado ponente: Clara Inés Vargas Hernández] (08 de abril de 2005).

Corte Constitucional, sala novena de revisión, sentencia T-951, [Magistrado ponente: Luis Ernesto Vargas Silva] (19 de diciembre de 2013).

Corte Constitucional, sala octava de revision, sentencia T- 246, [Magistrado ponente: Martha Victoria Sáchica Méndez] (30 de abril de 2015).

Corte Constitucional, sala octava de revisión, sentencia T- 623, [Magistrado ponente: Alvaro Tafur Galvis] (08 de agosto de 2002).

Corte Constitucional, sala plena, sentencia C-543, [Magistrado ponente: Jose Gregorio Hernández Galindo] (01 de octubre de 1992). 
Corte Constitucional, sala plena, sentencia C-590, [Magistrado ponente: Jaime Cordoba Triviño] (08 de junio de 2005).

Corte Constitucional, sala plena, sentencia SU- 627, [Magistrado ponente: Mauricio González Cuervo] (01 de octubre de 2015).

Corte Constitucional, sala plena, sentencia SU-1219, [Magistrado ponente: Manuel José Cepeda Espinoza] (21 de noviembre de 2001).

Corte Constitucional, sala primera de revisión, Sentencia T- 761, [Magistrado ponente: María Victoria Calle Correa] (07 de octubre de 2011).

Corte Constitucional, sala primera de revisión, sentencia T-474, [Magistrado ponente: María Victoria Calle Correal (13 de junio de 2011).

Corte Constitucional, sala quinta de revisión, sentencia T-869, [Magistrado ponente: Rodrigo Escobar Gil] (19 de octubre de 2006).

Corte Constitucional, sala septima de revisión, sentencia T-1031, [Magistrado ponente: Eduardo Montealegre Lynett] (27 de septiembre de 2001).

Corte Constitucional, sala tercera de revision, sentencia T-001, [Magistrado ponente: Jose Gregorio Hernández Galindo] (03 de abril de 1992).

Corte Constitucional, sala tercera de revisión, sentencia T-774, [Magistrado ponente: Manuel José Cepeda Espinoza] (13 de agosto de 2004).

Cuéllar, N. L. (2002 de Diciembre de 2002). ¿Tutela contra tutela? Análisis a la luz del desarrollo jurisprudencial de la Corte Constitucional. Obtenido de Revista de Derecho del Estado: http://revistas.uexternado.edu.co/index.php/derest/article/view/835/791

Ferrer Mac-Gregor, E. (2006). El Amparo Iberoamericano. Estudios Constitucionales(2), 39-65. Obtenido de http://www.redalyc.org/ pdf/820/82040103.pdf

Garzón Buenaventura, E. F. (2016). Derechos innominados en el sistema interamericano. Derecho constitucional, 11-23. doi: http://dx.doi. org/10.16925/di.v18i24.1520

Gómez, J. G. (21 de Julio de 2014). Análisis Jurídico: Tutela contra sentencias de tutela y nulidad de fallos de la Corte Constitucional. . Obtenido de La voz del derecho: http://www.lavozdelderecho.com/ index.php/opinion/analisis-juridico/item/2449-tutela-contra-sentencias-de-tutela-y-nulidad-de-fallos-de-la-corte-constitucional 
Paz, M. C. (2012). Derechos fundamentales innominados como parte de las garantias del derecho a la salud. El caso colombiano. Gaceta Medica de Mexico, 406-410.

Presidencia de la República de Colombia. (04 de septiembre de 1991). Decreto 2067. "Por el cual se dicta el régimen procedimental de los juicios y actuaciones que deban surtirse ante la Corte Constitucional”. Bogotá D.C.

Presidencia de la República de Colombia. (19 de Noviembre de 1991). Decreto 2591. Por el cual se reglamenta la acción de tutela consagrada en el artículo 86 de la Constitución Política. DO: 40.165. Obtenido de http://www.corteconstitucional.gov.co/lacorte/DECRETO\%20 2591.php

Torres Ruda, Y. E. (2014). La Acción de Tutela en Colombia: un estudio sobre sus transformaciones jurídicas (Tesis de grado, Universidad católica de Colombia). Obtenido de http://repository.ucatolica.edu.co/bitstream/10983/2674/1/pdf\%20LA\%20ACCIÓN\%20DE\%20TUTELA\%20EN\%20COLOMBIA\%20UN\%20ESTUDIO\%20SOBRE\%20 SUS\%20TRANSFORMACIONES\%20JURIDICAS.pdf

Véscovi, E. (2006). Teoria General del Proceso. Bogotá, Colombia: Temis.

Vivas Barrera, T. G. (2012). El Amparo mexicano y la Acción de tutela Colombiana. Un ejercicio de derecho constitucional comparado en Latinoamerica. Pensamiento jurídico(33), 13-66. Obtenido de http:// www.bdigital.unal.edu.co/36820/1/37883-168738-2-PB.pdf 